\title{
LÍNGUA, VARIAÇÃO E LITERATURA: INTERSEÇÕES NECESSÁRIAS PARA O ENSINO
}

Laila Hamdan (UEMG)

Resumo: Este estudo discute a importância da presença da literatura no currículo escolar, uma vez que assumida como elemento humanizador, responsável fundamental pela superação do preconceito linguístico. Essa possibilidade é estabelecida a partir do letramento literário construído em ensino de língua que perpassa a variação. $O$ objetivo é apresentar elementos teóricos relacionados ao ensino, ao letramento literário e à variação organizados e originados em posicionamentos que promovem e ampliam o direito à literatura como valor incompressível (CANDIDO, 2011). Para tal, consideraram-se fundamentos teóricos sobre literatura e o seu lugar na escola e, portanto, sua função como componente curricular, sobre letramento e sobre ensino de língua e variação, percorrendo definições e práticas que promovem o desenvolvimento da habilidade linguística e consequente letramento literário. Como resultado alcançou-se a comprovação da importância da literatura no currículo escolar bem como a construção de práticas que ampliam o letramento literário em sua função humanizadora, portanto propiciadoras de inclusão social, uma vez que, neste espaço, está o olhar sobre a variação linguística e o ensino.

Palavras-chave: Ensino; Letramento; Literatura; Variação linguística.

Abstract: This study discusses the importance of the presence of literature in the school curriculum, since it is assumed as a humanizing element, fundamentally responsible for overcoming linguistic prejudice. This possibility is established from the literary literacy constructed in language teaching that permeates the variation. The objective is to present theoretical elements related to teaching, literary literacy and variation organized and originated in positions that promote and expand the right to literature as an incompressible value (CANDIDO, 2011). For this, theoretical foundations about literature and its place in school were considered and, therefore, its function as a curricular component, on literacy and on language and variation teaching, going through definitions and practices that promote the development of linguistic skills and consequent literary literacy. As a result, we have 
achieved proof of the importance of literature in the school curriculum as well as the construction of practices that expand literary literacy in its humanizing function, therefore propitiating social inclusion, since, in this space, there is a look at linguistic variation and teaching.

Keywords: Teaching; Literacy; Literature; Linguistic variation.

\section{INTRODUÇÃO}

Este estudo aborda a relação entre literatura, inclusão e ensino considerada fundamental como elemento humanizador e sua presença nas aulas de língua, destacandose, inicialmente, definições que perpassam o estudo do tema, uma vez que há, historicamente, várias abordagens sobre ele. Assim, tratou-se do conceito de literatura e suas variações no tempo e do espaço que ocupa na sociedade para se chegar às discussões seguintes como a utilidade da literatura e sua instalação como bem incompressível em função humanizadora, principalmente, de acordo com o pensamento de Candido (2011, p.171). A literatura como componente curricular e sua relação com as escolas e com os envolvidos no processo ensino-aprendizagem foi também observada, construindo-se a proposta de olhar sobre o texto literário em atividades desenvolvidas que podem proporcionar a instalação do estudo da literatura como elemento que se constrói a partir da expressão linguística, proporcionando a inclusão social. Almeja-se interferir em percepções acerca do sujeito inserido em seu meio social, 
provocando o desenvolvimento do letramento literário e, consequentemente, o aperfeiçoamento da habilidade na lida com a língua, em consonância com a variação e não com o mito da uniformidade do português brasileiro (ILARI; BASSO, 2014, p.151).

Fique marcado que a pretensão deste estudo é contribuir para o ensino de literatura ou de língua portuguesa a partir de marcos teóricos já estabelecidos. O objetivo é apresentar relações entre o ensino de literatura, o letramento literário, o ensino de língua portuguesa e o fenômeno da variação linguística que promovem e ampliam o direito à literatura e, consequente, inclusão social, uma vez que se assume este valor como bem incompressível e como propiciador da superação do preconceito linguístico. Para tal, consideraramse fundamentos sobre literatura, sobre letramento e sobre variação e seus espaços na escola e, portanto, sua função como componente curricular.

Nessa pretensão, justifica-se o estudo, uma vez que a constante busca de reflexões e análises acerca de temas que participam hodiernamente da realidade educacional, social e, consequentemente, cultural são necessários e promovem de forma ampla o aperfeiçoamento dos envolvidos e interessados na questão. Em caráter mais pontual, justifica-se também 
como tentativa de promoção para o trabalho cotidiano do professor nas suas práticas em sala de aula. A literatura, a leitura literária e o letramento, quase sempre, são vistos como instrumentos para se alcançar algum outro conhecimento, ou seja, são ferramentas e não objetivos. Contrariamente, as propostas deveriam caminhar em outra perspectiva, função essencial da educação, portanto da escola: colaborar para a formação de sujeitos cidadãos plenos em sua tarefa constante de aprimoramento social e coletivo.

Este estudo, então, percorreu definições e práticas que promovem o letramento literário, em demonstrações da sensibilidade necessária aos envolvidos com ele e, principalmente, com o ensino. Alternativas didáticas que anulem a percepção de que literatura e ensino de língua estão distantes da realidade de todos (Português é uma língua muito difícil! Imaginem a literatura!) devem ser buscadas e construídas a partir de reflexões acerca do que é literatura, de sua função no currículo escolar e de como propiciar o letramento literário, elemento de humanização. Como resultado, espera-se a superação de explicações simplificadoras que justificam modismos e imobilismos e também a percepção da importância da literatura no currículo escolar bem como a ampliação do letramento 
literário em sua função humanizadora a partir de práticas, na lida com o ensino de língua.

\section{LITERATURA: ESTABELECENDO O ESPAÇO}

Inicialmente, é necessário que se busquem razões para que a literatura faça parte dos currículos escolares. Para tanto, cabe refletir sobre o lugar da literatura na sociedade e sobre sua relação com a cidadania. Faz-se necessário, também, estabelecer demarcações sobre o conceito de literatura uma vez que há controvérsias críticas e teóricas, principalmente, devido à sua abrangência semântica. Isso porque:

Primitivamente, o vocábulo designava o ensino das primeiras letras. Com o tempo, passou a significar "arte das belas letras" e, por fim, "arte literária". Até o século XVIII, preferiu-se o termo "poesia", ao qual se atribuía sentido solene e elevado. Somente a partir do século XIX é que a palavra "Literatura" entrou a ser empregada para definir uma atividade que, além de incluir os textos poéticos, abrangia todas as expressões escritas, mesmo as científicas e filosóficas. (MOISÉS, 2004, p.311)

Como se comprova nas palavras anteriores, a amplitude semântica e a conexão com a palavra escrita podem ser percebidas até a atualidade, uma vez que, tradicionalmente, relaciona-se literatura à escrita. Isso pode-se levar ao seu possível distanciamento do cotidiano das pessoas, uma vez 
que a escrita exige maior elaboração para o expressar-se e se faz menos acessível na realidade educacional brasileira.

Da Antiguidade greco-latina à atualidade, a Literatura recebeu definições que iam de seu estabelecimento como imitação, ou seja, como tentativa de recriação da realidade do mundo; até a um tipo de conhecimento expresso por palavras polivalentes. Note-se que o percurso não é excludente, mas que há imbricamento das definições, considerando-se, para este estudo, sua relação intrínseca com a subjetividade, com a expressão artística. Em destaque, as palavras de Antonio Candido:

A literatura corresponde a uma necessidade universal que deve ser satisfeita sob pena de mutilar a personalidade, porque pelo fato de dar forma aos sentimentos e à visão do mundo ela nos organiza, nos liberta do caos e portanto, nos humaniza. Negar a fruição da literatura é mutilar nossa humanidade. (Apud COSSON, 2014, p.15)

Reafirmando as palavras anteriores de Candido, Cosson (2014, p.15) elabora uma metáfora para inserir a literatura na vida do homem. Ela se faz presente, uma vez que é parte do "corpo" que, unida a outras partes, o constroem. Ele diz que "Ao corpo físico, somam-se um corpo linguagem, um corpo sentimento, um corpo imaginário." O corpo linguagem retrata o mundo, que é da forma que a linguagem permite 
dizer, assim, quanto mais se usa a língua, mais extenso é o corpo linguagem e, reciprocamente, maior é o mundo. A relação é de um "círculo virtuoso", uma vez que linguagem e mundo se constroem, se fazem e se refazem em constante relação dialógica. "E constituímos o mundo basicamente por meio das palavras. [...] quanto mais eu uso a língua, maior é o meu corpo linguagem e, por extensão, maior é meu mundo" (COSSON, 2014, p.16). E a possibilidade de ampliação é extensa e inumerável, porque as palavras estão presentes nas relações estabelecidas em sociedade e prontas para o uso, porque são de todos, elaborando o sentido para essas relações. Confirmando, "Ao usar as palavras, eu as faço minhas do mesmo modo que você, usando as mesmas palavras, as faz suas. É por esse uso, simultaneamente individual e coletivo, que as palavras se modificam, se dividem e se multiplicam, vestindo de sentido o fazer humano" (COSSON, 2014, p.16).

Nesse percurso, considerem-se também as palavras de Bakhtin (2011, p.290): “As palavras não são de ninguém, em si mesmas nada valorizam, mas podem abastecer qualquer falante e os juízos de valor mais diversos e diametralmente opostos dos falantes." Delas, considera-se fundamentalmente a propriedade social, porque estabelecem-se em conjunto, em trabalho de comunicação discursiva, portanto em 
abertura à inclusão, na medida que leva à necessidade do outro em constante atitude responsiva.

Dessa feita, justifica-se a resposta à pergunta de Rojo (2009, p.7): "Que letramentos fomentar?" Assume-se que o letramento literário, uma vez que a educação linguística devese apoiar em letramentos multissemióticos, em letramentos críticos e protagonistas, em letramentos múltiplos. Este apresentando-se como possibilidade dominante, porque o papel social da literatura está presente na ideia de "literatura" como toda produção cultural presente na sociedade, elaborada a partir das palavras, trazendo como novo o que já faz parte dessa sociedade. Ou seja, a literatura não mente ao tornar real o imaginário por meio da linguagem, mas ultrapassa o significante instaurando sentidos, pois o texto literário tem caráter polifônico na medida em que é voz produzida socialmente, é voz produzida por várias vozes. "O outro está presente, portanto, de forma assumida no discurso literário, e mais presente nele que em outros discursos" (PAULINO, Apud PAIVA, 2003, p.13).

Considerando que "Todos os diversos campos da atividade humana estão ligados ao uso da linguagem." (BAKHTIN, 2011, p.261), consequentemente, como os campos da atividade humana são variáveis e inesgotáveis, a linguagem 
se apresenta também como multiforme e produtiva. Nessa medida, confirmam-se as palavras de Candido (2011, p. 176) referentes ao aspecto social da literatura:

Chamarei de literatura, da maneira mais ampla possível, todas as criações de toque poético, ficcional ou dramático em todos os níveis de uma sociedade, em todos os tipos de cultura, desde o que chamamos de folclore, lenda, chiste, até as formas mais complexas e difíceis da produção escrita das grandes civilizações.

Assim, o movimento seguinte do estudo busca estabelecer a utilidade da literatura, uma vez que já se construiu, mesmo que incipientemente, seu espaço como elemento construtor do "corpo" sociedade, a partir do corpo língua/linguagem, promovendo, consequentemente a percepção do outro e, destarte, o reconhecimento da variação como inerente a esse corpo linguagem, uma vez que múltiplo.

\section{LITERATURA: ESTABELECENDO A UTILIDADE}

Segundo Antonio Candido (2011), para além de puramente função social, a literatura tem efeito libertador, isso porque pode anular o estabelecimento da rigidez dos estratos sociais. Por si só, esse argumento já justifica a presença da literatura como componente curricular, no ensino de língua, uma vez que abarca o fenômeno da variação. Especificamente, considere-se a realidade de que a injustiça social constrange 
e a insensibilidade frente à miséria assusta e leva à busca de melhores padrões sociais de comportamento e de conhecimento, uma vez que essa realidade já não é indiferente à sociedade. Assim, discute-se se a literatura é um direito de todos, se faz parte dos direitos humanos. "Por quê? Porque pensar em direitos humanos tem um pressuposto: reconhecer que aquilo que consideramos indispensável para nós é também indispensável para o próximo" (CANDIDO, 2011, p.174). Então, se é fator de humanização, é um direito de todos e, portanto, deve ter espaço garantido nos currículos escolares, presente no de ensino de língua. E, dessa maneira, tornam-se fundamentais as práticas sociais de letramento constituídas a partir do desenvolvimento da leitura e da escrita, porque "O contato com uma diversidade de textos e obras há de permitir ao aluno descobrir utilizações estéticas da Língua, segundo várias perspectivas e finalidades, e modos de ler, nomeadamente os indutores da leitura de textos literários" (REIS, Apud PANIAGO; DUARTE, 2016, p.36).

Comprovando a função social da literatura, Cândido (2011), utilizando o pensamento de Louis-Joseph Lebret, divide os bens da humanidade em "bens compressíveis" e "bens incompressíveis", imbricados na questão dos direitos humanos, e insere a discussão sobre o direito à literatura 
nesse espaço. A distinção entre eles, mesmo com uma fronteira tênue, estabelece que bens incompressíveis são os que não devem ser negados a ninguém, porque asseguram a sobrevivência física e a integralidade espiritual. Mesmo a literatura fazendo parte desse conjunto de bens, o que se apresenta é a realidade de que o que é indispensável a uma camada social não necessariamente o é para outra, ou seja, o valor depende da necessidade relativa da coisa. Surge, assim, a questão de ser indispensável para todas as camadas sociais ou apenas para aquelas mais privilegiadas cultural e economicamente, uma vez que os bens incompressíveis, além de assegurarem a sobrevivência física, promovem a integridade espiritual.

Reiterando, a literatura aparece como "todas as criações de toque poético, ficcional ou dramático", ou seja, produto da cultura humana, uma necessidade universal, um direito de todos e que precisa ser satisfeito. "[...] é o sonho acordado das civilizações correspondendo a uma necessidade universal, que precisa ser satisfeita e cuja satisfação constitui um direito" (CANDIDO, 2011, p.176), surgindo como fator de equilíbrio social, uma vez que intrinsecamente ligada ao domínio da língua e do reconhecimento de suas variações. Dessa maneira, portanto, justifica-se como fundadora de valores 
e, dialogicamente, como crítica desses mesmos valores. Paradoxalmente, confirma e nega; propõe e denuncia; apoia e combate, por isso é inerente à instrução e à educação, enfrentando, como ferramenta dialógica, os problemas sociais. Assim, não há equilíbrio social sem a literatura, considerando-a o conjunto das manifestações culturais que cada sociedade cria de acordo com suas crenças, com seus impulsos, sentimentos, normas para estabelecer em cada um a presença e atuação deles (2011, p.176-177).

Consubstanciando seu papel contraditório e humanizador, a literatura tira as palavras do nada e as dispõe como todo articulado, como acontecimento da comunicação discursiva, reiterando o pensamento de Bakhtin (2011). A organização da palavra comunica-se ao espírito e o leva a se organizar e, em seguida, organiza o mundo; desde as formas mais simples. Considera-se a mensagem inseparável do código, mas o código é a condição que assegura seu efeito, é a "fusão inextrincável da mensagem com a organização. O conteúdo só atua por causa da forma" (CANDIDO, 2011, p.180), é par indissolúvel para o maior/melhor significado.

Assim, observam-se três aspectos na realidade do ensino de literatura, de língua: sua função na construção de objetos autônomos, como estrutura e significado; sua função 
como forma de expressão; e sua função como forma de conhecimento. Do amálgama delas, chega-se ao seu poder humanizador como função essencial, como propiciadora da superação de preconceitos, fundamentalmente o linguístico, uma vez que não anula a variação, ou melhor, a variação está presente nesse amálgama. "A eficácia humana é função da eficácia estética e, portanto, o que na literatura age como força humanizadora é a própria literatura, ou seja, a capacidade de criar formas competentes" (CANDIDO, 2011, p.184).

Consequentemente, "as utilizações estéticas da língua deveriam ocupar, com efeito, um lugar central na aprendizagem da Língua Portuguesa, a começar pelo préescolar, dado que intensificar a relação lúdica da criança com a linguagem configura um momento prévio e inicial do gosto literário" (PANIAGO; DUARTE, 2016, p.37), porque propiciam situações de letramento que superam a simples compreensão da informação, mas alcançam as possibilidades de uso dela inseridas em seu cotidiano. A humanização se consolida no fazer literatura (escritor e leitor; locutor e interlocutor) porque possibilita e promove traços essenciais dessa humanização como o "exercício da reflexão, a aquisição do saber, a boa disposição para o próximo, o afinamento das emoções, a capacidade de penetrar nos problemas da vida, 
o senso da beleza, a percepção da complexidade do mundo e dos seres, o cultivo do humor" (CANDIDO, 2011, p.182).

Nesse estabelecimento, a realidade dos direitos humanos se instala, uma vez que a melhor organização da sociedade é feita de maneira a garantir uma distribuição equitativa de bens - do lazer indispensável à literatura; a garantir a luta pelos bens culturais populares ou eruditos, construídos por homens e sua eficácia gerada pela eficácia estética, possibilitando a intercomunicação entre os níveis culturais o que, por sua vez, promove a popularização humanizadora da literatura. Encerrando esta seção, trazem-se, ainda, as palavras de Candido (2011, p.193):

Portanto, a luta pelos direitos humanos abrange a luta por um estado de coisas em que todos possam ter acesso aos diferentes níveis da cultura. A distinção entre cultura popular e cultura erudita não deve servir para justificar e manter uma separação iníqua, como se do ponto de vista cultural a sociedade fosse dividida em esferas incomunicáveis, dando lugar a dois tipos incomunicáveis de fruidores. Uma sociedade justa pressupõe o respeito aos direitos humanos, e a fruição da arte e da literatura em todas as suas modalidades e em todos os níveis é um direito inalienável.

Consolida-se assim a justificativa do ensino da literatura e, considerando que "Sou quem sou, porque somos todos 
nós ${ }^{1 "}$, causa ou explicação, insere-se na realidade educativa da atualidade a importância da escola, da sala de aula, do ensino de língua, uma vez que espaços privilegiados das relações ensino-aprendizagem, mesmo que não únicos.

\section{LÍNGUA E ENSINO: ESTABELECENDO A RELAÇÃO COM A VARIAÇÃO, EM LETRAMENTO LITERÁRIO}

As produções literárias satisfazem necessidades básicas do ser humano, instalando-se como bens incompressíveis, uma vez que necessários como elementos humanizadores e, fundamentalmente, como organizadores dos espaços humanos porque promovem a percepção desses espaços e acuram a visão sobre eles. Retomando a metáfora já referida de Cosson (2014, p.16),

O corpo linguagem, o corpo palavra, o corpo escrita encontra na literatura seu mais perfeito exercício. A literatura não apenas tem a palavra em sua constituição material, como também a escrita é seu veículo predominante. A prática da literatura, seja pela leitura, seja pela escritura, consiste exatamente em uma exploração das potencialidades da linguagem, da palavra e da escrita, que não tem paralelo em outra atividade humana. Por essa exploração, o dizer o mundo (re)construído pela força da palavra, que é a literatura, revela-se como prática fundamental para a constituição de um sujeito da escrita.

1 Oráculo da filosofia Ubuntu. 
Comprova-se com essas palavras o relevante espaço que deve ser construído pela escola, no ensino de língua para o estabelecimento da literatura e o reconhecimento do fenômeno da variação. Inicialmente, porque a escola se faz, tradicionalmente, responsável pelo acesso à escrita que, por sua vez, é elemento fundamental numa sociedade letrada. A escrita, neste universo, ocupa lugar central, porque praticamente todas as criações humanas passam por ela, elemento privilegiado e, portanto, poderoso instrumento de superação de diferenças sociais e culturais. "A escrita é, assim, um dos mais poderosos instrumentos de libertação das limitações físicas do ser humano" (COSSON, 2014, p.16).

Melhor dizendo, a escola promove o letramento, por meio da palavra escrita, do ensino de língua, fatores de acesso à literatura, garantindo função essencial da construção e reconstrução constantes da palavra, humanizando os envolvidos na sua prática. Considerando o papel fundador da escola ser formar cidadãos responsáveis por uma sociedade mais humana, imbrica-se aí a literatura em sua força humanizadora e, portanto, também de formação do cidadão, superando as barreiras do preconceito. A literatura então tem uma função a cumprir no espaço escolar e, por sua vez, passa a ser (também) função escolar, consubstanciandose a escola como lugar privilegiado do letramento literário. 
É possível, de acordo com Paniago e Duarte (2016), escrever com a leitura de textos literários, é possível entender que as diferenças são inerentes aos seres e, portanto, há linguagens, há línguas, há variações.

Contrariamente, o que se percebe, muitas vezes, é o lugar nenhum da literatura nos ambientes escolares, uma vez que o espaço da literatura na escola parece enfrentar um de seus momentos mais difíceis. Examinando a carga horária disponível para a literatura, comprova-se sua perda de espaço na educação básica, nas aulas de língua e em cursos de graduação em Letras. Para se superar essa lacuna, promovendo a popularização da literatura, devese preocupar incialmente com a percepção/conhecimento do que seja a literatura para todos os envolvidos: alunos, professores, profissionais da educação, verificando como se estabelecem as relações entre educação, escola e literatura. Os estudos de Antônio Candido (2011) aqui citados são referências para o amadurecimento necessário sobre o tema, uma vez que, como se comprovou, é fator de humanização, porque provoca a anulação e/ou minimização das distâncias entre os homens (função fundamental da escola), reiterando, promove a superação de preconceitos vários, fundamentalmente, o preconceito linguístico. 
Superam-se também as distâncias na percepção do outro e sabê-lo como parte do todo pode favorecer o ensino. Inicialmente, para tal, move-se para a literatura como fonte inspiradora, então em encontro com o outro e, principalmente, consigo mesmo. Dessa forma, é preciso ter critérios seguros para abordar o problema dos bens incompressíveis, seja do ponto de vista individual, seja do ponto de vista social.

Comprova-se o posicionamento com palavras de Zilberman (2010, p.18),

a própria ação de ensinar a ler e escrever leva o indivíduo a aceitar o fato de que lhe cabe assimilar os valores da sociedade. [...] Mesmo insistindo na qualidade cognitiva e na importância do ato de ler, enquanto mediador privilegiado das relações do eu com o mundo, ele pode vir a exercer um papel coercitivo quando incorporado, integral, asséptica ou acriticamente, a interesses pragmáticos e indiretos, [...] interesses diferentes daqueles que são depositados na leitura e que justificam a reivindicação de uma atitude ampla por parte da comunidade que garanta sua difusão por todos os seus segmentos.

Comprovando a eficácia da proposta, Zilberman (2010, p.130) destaca ainda que, quando a noção de literatura se alarga e acolhe outras modalidades de expressão diversas já 
sacramentadas, o ensino encontra perspectivas inovadoras. Porém, sabe-se que, devido à política cultural pouco contundente e produtiva, o acesso ao livro e à leitura é restrito. Somado a isso, o ensino se apresenta, muitas vezes, preso a espartilhos herdados da história literária.

Reduz-se o potencial diferenciador na formação humanística, intelectual e cognitiva a mero processo de datação e caracterização, com uma relação de obras e de seus autores; perde-se a formação do hábito rico e construtivo ao não se mostrar o mundo fantástico dentro do mundo que se vive, formando leitores literários em face da melhor postura em relação ao texto. Consequentemente, há a redução do papel do professor a mero reprodutor do que já se está estabelecido e da anulação de seu papel de pesquisador e de ser reflexivo frente ao conhecimento que dever ser o seu ethos. Esquecem-se de que

a sala de aula é o espaço para o trânsito
de ideias e concretização de uma
aspiração da democracia: a de que
todos tenham oportunidades iguais de
acesso ao conhecimento e de pesquisar
novas tecnologias enquanto condição do
progresso social e da emancipação política.
(ZILBERMAN, 2010, p.139)

Consolidando o espaço privilegiado de instalação da literatura e, portanto, de humanização. 
Parafraseando Célia Pedrosa (2005), cada aluno é a metonímia da própria realidade social, por isso a função do professor na tarefa de provocar o sucesso do ensino da literatura relaciona-se sobremaneira à possibilidade de construção unívoca do progresso e do futuro, contra o uso homogeneizador e alienante da técnica pela técnica. Se assim não for, a formação humanística perde o sentido tendendo a ser vista apenas como erudição ornamental. A liberdade e sua instrumentalização são possibilidades sociais propiciadas pela literatura e não devem fazer parte de programas utópicos, mas de realizações concretas para o ensino. Sob esse ângulo, devem-se considerar as aulas de língua fundadas na concretude das relações socioculturais. Portanto, são eventos de prática social de responsabilidade da escola, uma vez que têm poder de humanização, de transformação individual e social. Supera-se a leitura como ato solitário e chega-se à interpretação, ao ensino/aprendizagem como ato solidário, porque "ao ler estou abrindo uma porta entre meu mundo e o mundo do outro" (COSSON, 2011, p.26).

Não se pode esquecer de que a literatura se realiza a partir da leitura, da língua que é, conforme ainda destaca Cosson (2011), um concerto de muitas vozes e nunca um monólogo. Assim, os sentidos alcançados são resultados 
de compartilhamento de visões do mundo entre homens no tempo e no espaço e a literatura que potencializa a relação, portanto, não pode ser inacessível, portanto é bem incompressível, direito de todos, direito do cidadão. Mas, mesmo assim, ninguém nasce sabendo literatura, por isso ao ensino cabe criar condições para favorecê-la e propiciála, conforme cita Zilberman (2010, p.98): “É que saber ler [...] não é somente um dom espontâneo; [...] é o resultado de uma educação aprimorada e cuidadosa." Uma educação que proporciona e propicia o desenvolvimento da leitura literária, porque

A leitura literária é associada à reflexão e à imaginação, quando estimula nossa percepção a romper com o automatismo da rotina cotidiana. Essa característica faz parte da função social da literatura. Ao entrar em contato com novas "realidades", o leitor adquire novas experiências, podendo refletir sobre sua vida, perceber sua própria realidade de outra maneira.

(PAIVA, 2006, p.25, grifos da autora)

Essa realidade depende, então, dos ditames relacionados à educação de forma geral e do ensino de literatura e de língua de forma específica; às possibilidades das leituras; às condições oferecidas pela escola; e às leituras do professor. Objetivamente, há várias práticas de ensino que se estabelecem como fundadoras do ensino. Especificamente, 
é por possuir essa função maior de tornar o mundo compreensível transformando sua materialidade em palavras de cores, odores, sabores e formas intensamente humanas que a literatura tem e precisa manter um lugar especial nas escolas.

(COSSON, 2014, p.17)

Retornando ao início do estudo, reitera-se a necessidade da percepção do ensino de literatura como passaporte para que se desenvolvam habilidades no aluno provocadoras da percepção aguçada do mundo, fazendo com que se anulem as diferenças sociais, uma vez que poderoso instrumento de instrução e de educação em sua plenitude, ou seja, tem função humanizadora. Nesse espaço, considere-se a percepção da variação linguística como elemento didático para se alcançar o ideal de ensino, "superando-se um conjunto de preceitos dogmáticos que não encontram respaldo nem nos fatos, [...] mas que se sustentam na cultura do erro e a sustentam, contribuindo para sua reprodução" (FARACO Apud ZILLES; FARACO, 2015, p.24).

\section{LETRAMENTO LITERÁRIO E VARIAÇÃO LINGUÍSTICA NO ENSINO DE LÍNGUA}

Considerando o desenvolvimento de habilidades que contemplam a literatura como bem incompressível, alcançando o letramento literário para que o cidadão faça parte da construção de um universo social mais solidário e 
amplo em suas potencialidades humanas, reitera-se a função precípua da escola e, neste espaço, a atuação do ensino de língua como o que organiza os caminhos mais produtivos a serem percorridos, como mediador da leitura escolhendo estratégias, porque

Diante de um texto literário, que é uma produção artística, espera-se que o leitor se sinta em interação com uma obra de arte. Essa interação lhe permite uma vivência que inclui, além de seu interesse intelectual, seu lado emocional: sua imaginação, desejos, medos, admirações. (PAIVA, 2006, p.21)

$\mathrm{Na}$ arte literária, toma-se por verdade o que foi inventado a partir de verdades, de possíveis realidades que se quer modificar, manter, enaltecer ou menosprezar. Nesse processo, há um diálogo rico entre autor e leitor, entre vozes da obra e vozes da obra com outras vozes de outras obras, enfim entre, literaturas e realidades, assumindo a dimensão imaginária potencializadora de reflexões, uma vez que pode tratar de qualquer tema, transformando os envolvidos de forma contundente. Assim,

O "eu" que está com a palavra num texto literário é muito mais do que o "eu" do autor [ou do leitor]. Este vai desdobrando, multiplicando-se, transformando-se, guiado pelo desejo, pela imaginação, pela intuição de como os outros seriam. [...] Quem escreve e quem lê a arte literária pode ser cachorro, 
cavalo ou gato, pode ser fada, pode ser velho, pode ser de outro sexo, pode viver em outra época, em outra casa, em outro país. (PAIVA, 2006, p.59)

Mesmo não se acreditando em fórmulas para ensinar a literatura, para ensinar a ler, a ouvir, considerem-se que há atividades promovedoras de sua presença na vida do cidadão. Algumas possibilidades reflexivas são apresentadas no próximo tópico.

\section{LETRAMENTO LITERÁRIO E VARIAÇÃO LINGUÍSTICA EM "CABELUDINHO"}

Considere-se o texto seguinte de Manuel de Barros, utilizado em questão do ENEM (2012):

\section{Cabeludinho $^{2}$}

Quando a Vó me recebeu nas férias, ela me apresentou aos amigos: Este é meu neto. Ele foi estudar no Rio e voltou de ateu. Ela disse que eu voltei de ateu. Aquela preposição deslocada me fantasiava de ateu. Como quem dissesse no Carnaval: aquele menino está fantasiado de palhaço. Minha avó entendia de regências verbais. Ela falava de sério. Mas todo-mundo riu. Porque aquela preposição deslocada podia fazer de uma informação um chiste. E fez. E mais: eu acho que buscar a beleza nas palavras é uma solenidade de amor. E pode ser instrumento de rir. De outra feita, no meio da pelada um menino gritou: Disilimina esse, Cabeludinho.

2 In www.inep.gov.br/educacao_basica/enem/provas/2012/caderno_enem2012_dom_azul. pdf Acesso em 20.Jul.2016. 
Eu não disiliminei ninguém. Mas aquele verbo novo trouxe um perfume de poesia à nossa quadra. Aprendi nessas férias a brincar de palavras mais do que trabalhar com elas. Comecei a não gostar de palavra engavetada. Aquela que não pode mudar de lugar. Aprendi a gostar mais das palavras pelo que elas entoam do que pelo que elas informam. Por depois ouvi um vaqueiro a cantar com saudade: Ai morena, não me escreve / que eu não sei a ler. Aquele a preposto ao verbo ler, ao meu ouvir, ampliava a solidão do vaqueiro. (BARROS, 2003)

A questão elaborada teve como objetivo discutir as diferentes possibilidades de uso da língua e os sentidos que esses usos podem produzir (destacando-se as expressões "voltou de ateu", "desilimina esse" e "eu não sei a ler"), com o objetivo de que o estudante perceba a ocorrência da valorização da dimensão lúdica e poética presente nos usos coloquiais da linguagem. Para além dessa possibilidade inerente à língua, notem-se as questões sociais e culturais que podem ser discutidas e trabalhadas a partir do "brincar de palavras" de Manuel de Barros.

Observando-se, primeiramente, a preposição "de" na expressão "voltou de ateu", percebe-se que o aparente vazio significativo das palavras que funcionam como copulativos, elementos que têm como principal função (supostamente) ligar palavras, sintagmas ou orações, para 
a ordenação lógica do enunciado, é apenas relativo, uma vez que permitem a expressão das mais diversas ideias. As preposições são vocábulos gramaticais que, como morfemas relacionais, estabelecem conexão entre palavras ou partes de uma frase, podendo ser subordinativos quando conectam termos em dependência sintática, ou coordenativos, quando não existe envolvimento sintático. Desempenham, por isso, funções relevantes relacionadas à enunciação, à organização do discurso e do texto e também à estruturação da frase em si. Conseguindo, muitas vezes, intuitos especiais, distantes de conteúdos informativos que palavras formais não conseguiriam, os conectivos prestam-se ao sentido, constituindo-se meios de expressão do domínio consciente e, portanto, quase nunca passíveis de análise e questionamento quanto aos seus valores.

Ainda assim, não são frutos do acaso, empregados inconsequentemente. A palavra em destaque supera mesmo as possibilidades aventadas, uma vez que promove a percepção do estado de coisas naquela realidade. A utilização da preposição pela personagem Vó consegue trazer ao texto a valorização de toda uma situação vivida pelo neto e por ela, colocando-os em contextos social e cultural específicos, em que se percebem valores de cada um e a importância 
que a aparência tem. No espaço construído, fantasiar de ateu pode mesmo equivaler a fantasiar de palhaço. O neto se mudou para o Rio e mudou sua aparência, tornando-se agora vestido "de ateu", em quase fantasia, uma vez que pode ser retirado aquele estado incorporado pelo neto. Ela impõe uma impressão religiosa ao aspecto observado no neto depois de sua volta do Rio. Segundo Hamdan (2018, p.168), "Muitos valores expressivos presentificam-se nos instrumentos gramaticais, mesmo que as palavras possam ser colocadas hierarquicamente de acordo com uma escala significativa estabelecida no texto."

Note-se na ocorrência que a fronteira entre palavras plenas e instrumentos gramaticais não é absoluta ou imutável e pode ser atravessada, servindo como sustentáculo de expressividade, resistindo à linha de demarcação e confirmando a importância fundamental dos conectores como elementos de sentido e de expressão de valores sociais e culturais, incorporando a pluralidade à unidade. Essas palavras relacionais marcam, no geral, relações lógicas e não de sentimento, emoções e conotações especiais. Mesmo que se distanciem da padronização linguística, fantasia, sentimento e valores especiais aparecem nos matizes conseguidos no emprego, chegando-se a tons inteiramente 
inusitados, resultantes de amálgama construído da mixagem lógico-emocional, rompendo o pensamento de que vocábulos gramaticais não têm funções significativas e não contribuem para a construção do sentido textual. Especificamente, destaque-se que "qualquer produção verbal é simultaneamente marcada do ponto de vista diacrônico, diatópico, diastrático e diamésico." (ILARI; BASSO, 2014, p.189), uma vez que são percebidos os lugares da Vó e de Cabeludinho, relativamente ao tempo da língua, ao lugar físico e social de cada um.

A potencialidade das formas da língua está sempre em renovação e sujeita à intenção expressiva do construtor de enunciados. A novidade provocada pelo uso incomum é de inegável efeito, nunca devendo ser menosprezada em favor das formas com valor lexical imanente, pois, por meio da genialidade do autor, as situações se alteram e se enriquecem. E mais, pode-se chegar à percepção de uma gama de cores, de realidades, de valores que tramam o texto e retratam a realidade configurando a literatura como responsável pela construção de expressividade bem como o letramento promovedor dessa potencialidade. O autor mesmo reforça o poder da preposição no próprio texto em “aquela preposição deslocada podia fazer de uma informação 
um chiste.", servindo a toda uma realidade social pungente que era a provável rejeição da avó ao novo visual do neto.

Na busca, na construção e observação da realidade que se constrói a partir do emprego inusitado da preposição, desenvolve-se a habilidade linguístico-literária e o consequente letramento, uma vez que, conforme palavras do autor, "eu acho que buscar a beleza nas palavras é uma solenidade de amor." A confirmação das palavras é originada exatamente da função humanizadora da literatura, porque conseguir perceber além da unidade significativa da língua e chegar-se, por meio da linguagem, ao contexto, à realidade de seres que possuem história, vontades, valores, conhecimentos é "solenidade de amor", é a percepção do outro em sua plenitude de tempo e de espaço. Fundamentalmente, reconhecer sua existência, sua originalidade, sem preconceito.

Em analogia a Bakhtin (2011, p.290), “As palavras não são de ninguém, em si mesmas nada valorizam, mas podem abastecer qualquer falante e os juízos de valor mais diversos e diametralmente opostos dos falantes," colocase a expressão de Manuel de Barros "palavra engavetada". A palavra sem ação, sem aplicação social ou cultural, fora de seu acontecimento, distante da comunicação discursiva, 
em estado de unidade da língua, e não um enunciado pleno, onde existe como voz de um sujeito histórico, não existe, nada significa.

Da mesma forma, a potencialidade criadora do falante na construção do verbo "disilimina" traz "um perfume de poesia à nossa quadra". Confirmando que as palavras são formas de brincar, são lúdicas e plurais instrumentos de socialização, pois são fluidas e maleáveis à vontade do sujeito e aprender a lidar com elas é promover letramento e ampliá-lo pela literatura. Modificações operadas denunciam ecletismo e evocam a supremacia lúdica do signo, da sintonia expressiva. O trabalho literário nas formas linguísticas promove a evocação de emoções denunciadoras da fertilidade da linguagem, superando o corriqueiro e comprovando a variação. As possibilidades expressivas ultrapassam a função puramente denotativa da linguagem e desvencilham-se de propósito normativo: "Aprendi nessas férias a brincar de palavras mais do que trabalhar com elas" (grifos nossos). Dessa feita, todos os elementos linguísticos formais são capazes de conteúdos emotivos, de exteriorização psíquica ou apelo, expressando os fatos da sensibilidade por meio da literariedade, socializando individualidades.

As palavras são criadas e recriadas com a função maior de extrapolar a sua significação primeira ou dar-lhe nuanças 
novas e especiais. Trazem sensações que se originam de sua materialidade, ou seja, de sua constituição morfemática, chegando a sugerir emotividade, contaminando o ambiente textual e contextual: um perfume de poesia à nossa quadra chegou a partir da forma disilimina. Esse processo acontece a todo momento na comunicação humana e em sua expressão de arte, a literatura, para fins ainda não utilizados, esbarrando no limite da norma, porque a palavra pode ser instrumento de rir, mostrando a criação inovadora e ressaltando o aspecto da emotividade, do ludismo, da variação

Por fim, outro processo inovador é marcado com o comentário de Manuel de Barros: Aquele a preposto ao verbo ler, ao meu ouvir, ampliava a solidão do vaqueiro. em $A i$ morena, não me escreve / que eu não sei a ler. Há ampliação da solidão do vaqueiro advinda do emprego da preposição junto ao verbo saber, transitivo direto, transformando-se para transitivo indireto com a regência da preposição $a$. saber a ler passa a ser maior do que saber ler, então a distância entre ele, vaqueiro, e a morena também se amplia, porque as cartas escritas por ela conseguirão superar o afastamento entre eles; a distância configurando-se como física, uma vez que existe saudade e (não) possibilidade da carta, já que só se escreve para os que estão distantes; e também social, uma vez que ela (a morena) sabe ler e escrever, mas ele 
(o vaqueiro), não. Neste espaço, encontram-se elementos para se discutirem questões sociais relativas ao analfabetismo, à necessidade do aprendizado da escrita, à importância dela na vida das sociedades letradas, bem como a eficiência expressiva do vaqueiro mesmo sem saber as letras. Há questões prementes acerca do tema e que podem ser debatidas a partir dos sentimentos e emoções advindos da construção. Além de estabelecer-se a conexão construída a partir do verbo ouvir: poder-se-ia somente ouvir o vaqueiro, posto que a expressão oral era sua única forma de verbalizar os seus sentimentos, pois ele não sabe ler, portanto, também não sabe escrever.

Nesse espaço, de acordo com llari e Basso (2014, p.180181), instala-se a variação diamésica, referente aos veículos ou meios de expressão que a língua utiliza, ou seja, a variação associada ao uso de diferentes meios ou veículos. "A variação diamésica compreende, antes de mais nada, as profundas diferenças que se observam entre a língua falada e a língua escrita." A solidão do vaqueiro é maior, uma vez que a variação ocorrida entre sua língua e a da morena se consolida nos meios diferentes de suas expressões. A solidão do vaqueiro se intensifica, se houver a compreensão da variação diamésica, do que se tem como distanciamento provocado pela ausência do letramento. 


\section{CONSIDERAÇÕES FINAIS}

Com este estudo, buscou-se apresentar questões que envolvem o ensino e suas imbricações com a literatura e o fenômeno da variação linguística, uma vez que apresentam caráter fundamentalmente social, porque têm função humanizadora e, portanto, incompressíveis. Para se chegar à proposta de atividades que promovem esse caráter humanizador, cumpriram-se percursos teóricos de definição (ou definições) dos temas, estabelecendo o espaço da literatura, do ensino e da variação. Da mesma forma, discutiu-se sua utilidade como elemento que faz parte da cultura do homem, por isso inerente a ele e, também e/ou por isso mesmo, relacionando sua presença inquestionável nos currículos escolares, uma vez que a escola se constitui (ou deveria) espaço privilegiado de ensino, de letramento.

Considere-se a discussão com o objetivo primeiro de se alcançar a função social da língua, da literatura, da variação em seu aspecto humanizador, sua instalação entre os bens incompressíveis a que se referiu Candido (2011) e a que se reportou este estudo. Desse modo, o ensino não se deve reduzir à simples utilização língua, de maneira cotidiana e trivial, mas conduzir todos a caminhos multidirecionais, abrindo espaços para a emoção, à interação, abandonando 
a rigidez formal e chegando-se ao letramento literário, ao reconhecimento da variação como fenômeno natural, levando-se, assim, à superação do preconceito linguístico. Letramento e variação que falam do homem, que conseguem efeitos de acordo com as experiências individuais e sociais, pois, a cada produção, é possível revigorar a criação com destreza aguçando os fios da sensibilidade, os retratos de experiências pessoais, desfazendo barreiras e imposições canônicas e, concomitantemente, renovando-as. O trabalho com a literatura, por fim, proporciona o desenvolvimento de consciência crítica, visto que a partir do letramento literário se instala o amadurecimento, provocando a (re)descoberta de potencialidades. A partir da descoberta do poder que têm, é tecida a literatura liberta de (pré)conceitos e alcançando um sujeito ativo no mundo, um sujeito artesão desse mundo. Afinal, é nos desvios que estão os araticuns mais maduros!

\section{REFERÊNCIAS}

BAKHTIN, Mikhail (2011). Estética da criação verbal. 6.ed. São Paulo: WMF Martins Fontes.

BARROS, M (2003). Memórias inventadas: a infância. São Paulo: Planeta. CANDIDO, Antonio (2011). Vários escritos. 5.ed. Rio de Janeiro: Ouro sobre Azul.

COSSON, Rildo (2014). Letramento literário: teoria e prática. 2.ed. 3ạ reimpressão. São Paulo: Contexto.

FARACO, Carlos Alberto; ZILLES, Ana Maria (2017). Norma linguística. São Paulo: Contexto. 
HAMDAN, Laila (2018). Ludismo verbal e literariedade: percursos de letramento. Divinópolis: Adelante.

ILARI, Rodolfo; BASSO, Renato (2014). O português da gente: a língua que estudamos; a língua que falamos. 2.ed. 5a reimpressão. São Paulo: Contexto.

MOISÉS, Massaud (2004). Dicionário de termos literários. 15.ed. São Paulo: Cultrix.

PAIVA, Aparecida; MARTINS, Aracy; PAULINO, Graça; VERSIANI, Zélia (Org.) (2003). Literatura e Letramento: espaços, suportes e interfaces. Belo Horizonte: Autêntica.

; PAULINO, Graça; PASSOS, Marta (2006). Literatura e leitura literária na formação escolar: caderno do professor. Belo Horizonte: Ceale.

PANIAGO, Maria de Lourdes Faria dos Santos; DUARTE, Isabel (2016). "Ensino de Português hoje: Brasil e Portugal, distâncias e confluências". In ORTIS-PREUSS, Elena; COUTO, Elza Kioto Nakayama N. do; RAMOS, Rui Manoel. Múltiplos olhares em linguística e linguística aplicada. São Paulo: Pontes.

PEDROSA, Célia (2005). "Poéticas do olhar na contemporaneidade". Literatura e Sociedade. (USP) São Paulo, 8, 82-103.

ROJO, Roxane (2009). Letramentos múltiplos, escola e inclusão social. São Paulo: Parábola.

ZILBERMAN, Regina (2010). A leitura e o ensino da literatura. São Paulo: Contexto.

ZILLES, Ana Maria Stahl; FARACO, Carlos Alberto (Orgs.) (2015). Pedagogia da variação linguística: língua diversidade e ensino. São Paulo: Parábola.

Laila Hamdan é Pós-Doutora pela Universidade Federal de Ouro Preto (UFOP); Doutora e Mestre pela Universidade do Estado do Rio de Janeiro (UERJ) e, atualmente, é professora efetiva da UEMG, onde atua nos cursos de Letras e Pedagogia (Graduação) e especialização (Orientação de TCC). Publicou Ludismo verbal e literariedade: percursos de Letramento 
(Editora Adelante), e A construção verbal observada no discurso do jornal "O Bom Ladrão" como denunciadora das ideias ultramontanas (Revista Cadernos de Linguagem e Sociedade - UNB). Faz parte da Comissão Científica da Abralin de Linguística Aplicada.

E-mail: lailaham@me.com

Recebido em 14 de julho de 2020 Aprovado em 06 de agosto de 2020 